\title{
Polyunsaturated fatty acid concentrations in young men and women consuming their habitual diets
}

\author{
Lucy Bakewell, Graham C. Burdge* and Philip C. Calder \\ Institute of Human Nutrition, Developmental Origins of Health and Disease Division, University of Southampton, Southampton \\ SO16 7PX, UK
}

(Received 18 October 2005 - Revised 21 February 2006 - Accepted 7 March 2006)

\begin{abstract}
Young women of reproductive age appear to have a greater capacity than men to convert the essential fatty acid $\alpha$-linolenic acid to DHA. The purpose of this study was to test the hypothesis that gender-related differences in $n$-3 PUFA metabolism are reflected in the concentrations of $n$ - 3 PUFA in plasma lipids. The subjects were healthy men $(n$ 13) and women $(n 23)$ aged $18-35$ years consuming their habitual diet. Dietary habits were assessed by food-frequency questionnaire. Venous blood samples were collected following an overnight fast. For the women, blood collection took place on the tenth day of their menstrual cycle. The fatty acid concentrations of plasma phosphatidylcholine, triacylglycerol, NEFA and cholesteryl esters were determined by gas chromatography. There were no significant differences between men and women in their consumption of protein, carbohydrate, total fat, alcohol, individual fatty acids and selected micronutrients. DHA concentration alone was significantly higher in plasma phosphatidylcholine $(31 \%, P=0.02)$, triacylglycerol $(71 \%, P=0.02)$ and NEFA $(33 \%, P=0.01)$, but not cholesteryl esters, in women compared with men. There were no significant differences between men and women in the concentrations of any other fatty acids measured. Overall, the present data support the suggestion that greater DHA synthesis in women than men results in a higher DHA concentration in plasma lipids.
\end{abstract}

Docosahexaenoic acid: Blood: Gender: Polyunsaturated fatty acids

PUFA are important for the function of cell membranes. They contribute significantly to the biophysical properties of the phospholipid bilayer by providing an appropriate environment for the activities of membrane-associated proteins (Mitchell et al. 2003). Some are substrates for the biosynthesis of messengers in signalling pathways (Lewis et al. 1990; Tilley et al. 2001). Modulation of the PUFA composition of the diet and in cell membranes, in particular the relative amounts of $n-3$ and $n-6$ fatty acids, produces significant changes in cell function. This has been studied extensively in the central nervous and immune systems (see reviews by Innis, 2000; Calder, 2003). Thus, optimal tissue function requires an adequate supply of PUFA for incorporation into cell membranes. Such demands may be met by the intake of PUFA in the diet, by a mobilisation of storage pools in adipose tissue and/or by the synthesis of the longer-chain unsaturated fatty acids, in particular arachidonic acid (20:4n-6; AA), EPA (20:5n-3) and DHA (22:6n-3), from their respective essential fatty acid precursors linoleic acid (18:2n-6) and $\alpha$-linolenic acid (18:3n-3; $\alpha$ LNA). The relative contribution of these pathways in meeting demands for PUFA is not known.

Dietary intakes of AA, EPA and DHA are substantially lower in the Western diet compared with their essential fatty acid precursors; linoleic acid intake is about 20 -fold greater than that of AA, and $\alpha \mathrm{LNA}$ intake is about 20-30-fold greater than EPA and DHA intake (Ministry of Agriculture, Fisheries and Food, 1997). This suggests that the conversion of linoleic acid to AA, and $\alpha$ LNA to EPA and DHA, may be important for providing AA, EPA and DHA for incorporation into the tissues. The biosynthesis of AA, EPA and DHA from essential fatty acids involves a common pathway (reviewed in Sprecher, 2002). Studies using stable isotope tracers or in which volunteers have increased their consumption of $\alpha$ LNA show that, in men or mixed groups of men and women, the apparent conversion of $\alpha$ LNA to EPA is low and the synthesis of DHA highly constrained (reviewed in Burdge, 2004). In contrast, stable isotope tracer studies of women alone indicate that the synthesis of EPA and DHA is greater in young women compared with men (Burdge \& Wootton, 2002; Pawlosky et al. 2003). Furthermore, women who used a $17 \alpha$-ethynyloestradiolbased oral contraceptive pill (OCP) had higher concentrations of labelled DHA in their circulation than those who did not (Burdge \& Wootton, 2002), which suggests that oestrogen may act as an agonist of DHA synthesis.

Giltay et al. (2004b) show that, when dietary $\alpha$ LNA, EPA and DHA intakes were controlled, women had a greater proportion of DHA in the plasma cholesteryl esters (CE) compared with men. The hormonal therapy of postmenopausal women with the hepatic oestrogen receptor agonist raloxifene or with conjugated equine oestrogens in combination with medroxy-progesterone increased plasma CE DHA concentration in a dose-dependent manner (Giltay et al. 2004a).

Taken together, these data suggest that women have a higher plasma DHA concentration than men owing to a greater 
capacity for DHA synthesis, and that this is due to the actions of oestrogens. It is unclear whether the difference in DHA concentration between men and women can only be detected when the diets of individuals are controlled for PUFA intake. If so, this observation would be of limited application to the general population. Because $\mathrm{CE}$ represent only one transport pool for PUFA in the blood, the impact in terms of the supply of DHA to the tissues would be limited if the greater DHA concentration in women than men was confined to $\mathrm{CE}$ alone. In the present study, we measured the concentration of PUFA in plasma lipids in young women consuming their habitual diet. In addition, in order to determine whether the PUFA content of the other major transport pools differed between men and women, we measured the fatty acid composition of plasma triacylglycerol (TAG), phosphatidylcholine (PC), NEFA and CE.

\section{Materials and methods}

\section{Subjects}

the subjects were healthy men and women aged between 18 and 35 years with a BMI of between 20 and $30 \mathrm{~kg} / \mathrm{m}^{2}$ (Table 1). The women included eleven who used an oestrogen-based OCP (dose $30-35 \mu \mathrm{g} / \mathrm{d}$ ) for at least 4 months and those who did not use an OCP. Their general health was assessed using a self-completed questionnaire, and volunteers who had endocrinological disturbance were excluded. Volunteers were also excluded if they smoked tobacco or took dietary vitamin or oil supplements. The women were all studied on day 10 of their menstrual cycle to prevent the influence of cyclic variations in plasma fatty acid composition (Mattsson et al. 1985).

\section{Dietary analysis}

Dietary analysis was carried out using a food-frequency questionnaire adapted from that used in the European Investigation into Cancer and Prevention study by the addition of questions relating specifically to the consumption of fish and other seafood (see Welch et al. 2002). The intakes of total macronutrients, individual fatty acids and micronutrients were determined using FoodBase version 3.1 Standard Edition (Institute of Brain Chemistry and Human Nutrition, London Metropolitan University, London, UK). Where the fatty acid composition of individual foods was not included in FoodBase, foods were purchased from commercial sources and analysed by gas chromatography (see later), and the database then modified.

Table 1. Characteristics of volunteers

(Values are means and standard deviations)

\begin{tabular}{|c|c|c|c|c|c|}
\hline & \multicolumn{2}{|c|}{ Men (n 13) } & \multicolumn{2}{|c|}{ Women (n 23) } & \multirow{2}{*}{$\frac{\text { Student's unpaired } t \text { test }}{P}$} \\
\hline & Mean & $\mathrm{SD}$ & Mean & $\mathrm{SD}$ & \\
\hline Age (years) & 26 & 5 & 23 & 4 & NS \\
\hline BMI $\left(\mathrm{kg} / \mathrm{m}^{2}\right)$ & $23 \cdot 3$ & $2 \cdot 8$ & $22 \cdot 7$ & $2 \cdot 3$ & NS \\
\hline Body fat (\%) & $18 \cdot 2$ & $3 \cdot 8$ & 28.6 & 4.4 & $<0.0001$ \\
\hline
\end{tabular}

\section{Analysis of body composition}

The proportion of body fat mass was determined by the bioelectrical impedance method using a BodyStat device (Bodystat Ltd, Douglas, Isle of Man, UK) as instructed by the manufacturer.

\section{Analysis of plasma fatty acid compositions}

Blood $(10 \mathrm{ml})$ was collected from a forearm vein into a tube containing heparin anticoagulant. Plasma was separated from cells by centrifugation, frozen and stored at $-20^{\circ} \mathrm{C}$.

Dipentadecanoyl PC, triheptadecanoin, heneicosaenoic acid and cholesteryl heptadecanoate were added to plasma $(0 \cdot 8 \mathrm{ml})$ as internal standards. Total plasma lipids were extracted with chloroform-methanol (2:1, v/v) by the method of Folch et al. (1957). Individual lipid classes were separated by solid-phase extraction using $100 \mathrm{mg}$ aminopropylsilica BondElut cartridges (Varian, Walton-on-Thames, Surrey, UK) as described (Burdge et al. 2000). Purified lipid fractions were transmethylated by incubation with methanol containing $2 \%$ (v/v) sulphuric acid at $50^{\circ} \mathrm{C}$ for $2 \mathrm{~h}$ (Burdge et al. 2000). Fatty acid methyl esters were recovered by extraction with hexane.

Fatty acid methyl esters were resolved by gas chromatography using an 6890 gas chromatograph (Agilent Technologies UK Limited, Stockport, UK) equipped with a $30 \mathrm{~m} \times$ $0.25 \mathrm{~mm} \times 0.25 \mu \mathrm{m}$ BPX-70 fused silica capillary column (SGE Europe Ltd, Milton Keynes, UK) and flame ionisation detection. Fatty acid methyl esters were identified by their retention times relative to standards (Sigma, Poole, Dorset, UK) and peak areas quantified using the Chemstation program (Agilent Technologies UK Ltd). The concentrations of individual fatty acids were calculated relative to the peak area of the appropriate internal standard and expressed as $\mu \mathrm{g} / \mathrm{ml}$ or as the proportion of total fatty acids in each lipid fraction.

\section{Statistical analysis}

The numbers of men and women who took part in the study provided statistical power of $80 \%$ for detecting a $10 \%$ difference between men and women in plasma PC DHA concentration at the $P<0.05$ level. Comparisons between men and women were by Student's unpaired $t$ test.

\section{Results}

Subjects

There were no significant differences in the age or the BMI of the subjects (Table 1). As expected, the proportion of body fat was $57 \%$ greater in women than men.

\section{Nutrient intakes}

Macronutrient, alcohol and selected vitamin and mineral intakes are summarised in Table 2. There were no significant differences between men and women in total energy, fat, carbohydrate or protein intake. The consumption of iron, folic acid and vitamins $\mathrm{B}_{12}, \mathrm{C}$ and $\mathrm{E}$ did not differ significantly between groups.

The intakes of individual fatty acids are summarised in Table 3. There were no significant differences between men 
Table 2. Macronutrient and selected vitamin and micronutrient intakes

(Values are means and standard deviations)

\begin{tabular}{|c|c|c|c|c|c|}
\hline & \multicolumn{2}{|c|}{ Men (n 13) } & \multicolumn{2}{|c|}{ Women (n 23) } & \multirow{2}{*}{$\frac{\text { Student's unpaired } t \text { test }}{P}$} \\
\hline & Mean & SD & Mean & SD & \\
\hline Energy (kcal/d) & 2237 & 476 & 2018 & 536 & NS \\
\hline Fat $(\mathrm{g} / \mathrm{d})$ & 81 & 18 & 67 & 25 & NS \\
\hline Protein (g/d) & 79 & 18 & 70 & 20 & NS \\
\hline Carbohydrate (g/d) & 302 & 58 & 280 & 81 & NS \\
\hline Alcohol $(g / d)$ & 15 & 20 & 13 & 13 & NS \\
\hline Iron (mg/d) & 14 & 4 & 16 & 6 & NS \\
\hline Vitamin $B_{12}(\mathrm{mg} / \mathrm{d})$ & 4 & 2 & 4 & 2 & NS \\
\hline Vitamin $E(\mathrm{mg} / \mathrm{d})$ & 11 & 5 & 9 & 4 & NS \\
\hline Vitamin C (mg/d) & 146 & 49 & 140 & 64 & NS \\
\hline Folic acid $(\mu \mathrm{g} / \mathrm{d})$ & 328 & 89 & 315 & 118 & NS \\
\hline
\end{tabular}

and women in the consumption of total saturated fatty acids, MUFA, total PUFA, $n$ - 3 PUFA and $n$-6 PUFA. The consumption of individual saturated fatty acids, MUFA and PUFA, and the ratios of total $n-6$ to $n-3$ PUFA and linoleic acid to $\alpha$ LNA, did not differ significantly between men and women (Table 3 ). The principal sources of $\alpha$ LNA were: fats and oils $27 \cdot 1 \%$, vegetables $17.3 \%$, meat $12.4 \%$, cereals $12.2 \%$, others $31.0 \%$ in men; fats and oils $15.3 \%$, vegetables $17.1 \%$, meat $5.1 \%$, cereals $29.3 \%$, others $33.2 \%$ in women. The principal sources of EPA and DHA were: fish $69.8 \%$, meat $11 \%$, poultry $10.4 \%$, eggs $5.1 \%$, others $3.8 \%$ in men; fish $78.3 \%$, meat $11 \%$, poultry $18.1 \%$, eggs $2.5 \%$, others $1.4 \%$ in women.

\section{Plasma fatty acid composition}

Total NEFA and PC concentrations were greater in women than men $(179 \%$ and $31 \%$, respectively; Table 4). There were no significant differences between groups in the concentrations of plasma TAG and CE. In order to prevent the influence of differences in the concentrations of total plasma lipids on the concentrations of individual fatty acids, the amounts of individual fatty acids are expressed as percentage total fatty acids within each plasma lipid pool.

Analysis of the fatty acid composition of plasma lipids showed specific differences between groups in the fractional concentrations of individual PUFA. The proportion of DHA was significantly greater in plasma TAG $(71 \%)$, NEFA (33\%), PC (31\%) and total plasma lipids (42\%) in women compared with men (Table 4). There was no significant difference between men and women in fractional DHA concentration in the $\mathrm{CE}$ fraction. Overall, the proportion of DHA in total plasma lipids was $42 \%$ greater in women than men (Table 4). There was no significant difference in the fractional concentration of EPA between men and women in any of the plasma lipid classes (Table 4). However, the proportion of EPA was $40 \%$ higher in women than men in total plasma

Table 3. Selected fatty acid intakes

(Values are means and standard deviations)

\begin{tabular}{|c|c|c|c|c|c|}
\hline & \multicolumn{2}{|c|}{ Men $(n 13)$} & \multicolumn{2}{|c|}{ Women (n 23) } & \multirow{2}{*}{$\frac{\text { Student's unpaired } t \text { tes }}{P}$} \\
\hline & Mean & SD & Mean & SD & \\
\hline Myristic (g/d) & 3.4 & 1.4 & $2 \cdot 5$ & 1.4 & NS \\
\hline Palmitic (g/d) & $14 \cdot 8$ & $3 \cdot 7$ & $12 \cdot 3$ & $5 \cdot 2$ & NS \\
\hline Stearic $(\mathrm{g} / \mathrm{d})$ & $7 \cdot 0$ & $2 \cdot 5$ & $5 \cdot 9$ & $2 \cdot 9$ & NS \\
\hline Total saturated (g/d) & 29.5 & $8 \cdot 6$ & $24 \cdot 1$ & $11 \cdot 2$ & NS \\
\hline Palmitoleic (g/d) & $1 \cdot 0$ & 0.4 & $0 \cdot 8$ & 0.4 & NS \\
\hline Vaccenic (g/d) & 1.4 & $2 \cdot 4$ & 0.3 & 0.5 & NS \\
\hline Oleic $(g / d)$ & $23 \cdot 3$ & $7 \cdot 1$ & $20 \cdot 0$ & $8 \cdot 4$ & NS \\
\hline Total monounsaturated $(\mathrm{g} / \mathrm{d})$ & $26 \cdot 8$ & $7 \cdot 2$ & $22 \cdot 2$ & $8 \cdot 7$ & NS \\
\hline Linoleic (g/d) & $12 \cdot 3$ & $5 \cdot 3$ & $10 \cdot 3$ & $4 \cdot 8$ & NS \\
\hline$\gamma$-Linolenic (mg/d) & 2 & 1 & 2 & 1 & NS \\
\hline Dihomo- $\gamma$-linolenic $(\mathrm{mg} / \mathrm{d})$ & 23 & 16 & 23 & 23 & NS \\
\hline Arachidonic (mg/d) & 103 & 58 & 103 & 77 & NS \\
\hline Total $n-6(\mathrm{~g} / \mathrm{d})$ & $12 \cdot 5$ & $5 \cdot 3$ & $10 \cdot 5$ & $4 \cdot 8$ & NS \\
\hline$\alpha$-Linolenic $(\mathrm{g} / \mathrm{d})$ & 1.4 & 0.6 & $1 \cdot 0$ & 0.5 & NS \\
\hline $\mathrm{EPA}(\mathrm{mg} / \mathrm{d})$ & 86 & 60 & 109 & 90 & NS \\
\hline $\mathrm{DHA}(\mathrm{mg} / \mathrm{d})$ & 130 & 112 & 159 & 127 & NS \\
\hline Total $n-3(\mathrm{~g} / \mathrm{d})$ & $1 \cdot 7$ & 0.6 & 1.4 & 0.5 & NS \\
\hline Total polyunsaturated $(\mathrm{g} / \mathrm{d})$ & $14 \cdot 2$ & $5 \cdot 7$ & $11 \cdot 8$ & $5 \cdot 1$ & NS \\
\hline$n-6: n-3$ & $7 \cdot 7$ & $2 \cdot 4$ & $8 \cdot 0$ & $3 \cdot 1$ & NS \\
\hline Linoleic: $\alpha$-linolenic & $9 \cdot 5$ & $3 \cdot 0$ & $10 \cdot 7$ & $3 \cdot 2$ & NS \\
\hline
\end{tabular}


Table 4. Plasma PUFA concentrations

(Values are means and standard deviations)

\begin{tabular}{|c|c|c|c|c|c|}
\hline & \multicolumn{5}{|c|}{ Concentration (\% total fatty acids) } \\
\hline & \multicolumn{2}{|c|}{ Men $(n 13)$} & \multicolumn{2}{|c|}{ Women (n 23) } & \multirow{2}{*}{$\frac{\text { Student's unpaired } t \text { tes }}{P}$} \\
\hline & Mean & SD & Mean & SD & \\
\hline \multicolumn{6}{|l|}{ Triacylglycerol } \\
\hline Linoleic & $19 \cdot 3$ & $4 \cdot 3$ & $17 \cdot 7$ & $1 \cdot 1$ & NS \\
\hline$\gamma$-Linolenic & $1 \cdot 2$ & 0.5 & $1 \cdot 4$ & $1 \cdot 0$ & NS \\
\hline Dihomo- $\gamma$-linolenic & $0 \cdot 7$ & 0.5 & 0.5 & 0.7 & NS \\
\hline Arachidonic & 1.6 & 0.3 & 1.5 & 0.5 & NS \\
\hline Total $n-6$ & $22 \cdot 8$ & 4.6 & $21 \cdot 1$ & $9 \cdot 7$ & NS \\
\hline$\alpha$-Linolenic & $1 \cdot 0$ & 0.5 & 0.9 & 0.6 & NS \\
\hline EPA & 0.3 & 0.2 & 0.5 & 0.4 & NS \\
\hline Docosapentaenoic $n-3$ & 0.6 & 0.1 & 0.6 & 0.4 & NS \\
\hline DHA & 0.7 & 0.3 & $1 \cdot 2$ & 0.9 & 0.02 \\
\hline Total $n-3$ & $2 \cdot 6$ & 0.9 & $3 \cdot 2$ & 1.6 & NS \\
\hline Total SFA & $30 \cdot 7$ & $4 \cdot 6$ & $32 \cdot 1$ & $4 \cdot 7$ & NS \\
\hline Total MUFA & $44 \cdot 0$ & $2 \cdot 9$ & $45 \cdot 8$ & $4 \cdot 3$ & NS \\
\hline \multicolumn{6}{|l|}{ NEFA } \\
\hline Linoleic & $13 \cdot 1$ & $2 \cdot 6$ & $11 \cdot 9$ & $2 \cdot 4$ & NS \\
\hline$\gamma$-Linolenic & 0.1 & 0.4 & 0.1 & 0.4 & NS \\
\hline Dihomo- $\gamma$-linolenic & $1 \cdot 2$ & $1 \cdot 7$ & 0.4 & 0.6 & NS \\
\hline Arachidonic & $1 \cdot 3$ & 0.7 & $1 \cdot 2$ & 0.4 & NS \\
\hline Total $n-6$ & $15 \cdot 7$ & 3.0 & 13.7 & 2.9 & NS \\
\hline$\alpha$-Linolenic & $1 \cdot 1$ & 0.4 & $1 \cdot 2$ & 0.4 & NS \\
\hline EPA & 0.01 & 0.01 & 0.1 & 0.2 & NS \\
\hline Docosapentaenoic $n-3$ & 0.2 & $0 \cdot 2$ & 0.3 & 0.2 & NS \\
\hline DHA & 0.8 & 0.4 & $1 \cdot 3$ & 0.6 & 0.01 \\
\hline Total $n-3$ & $2 \cdot 1$ & 0.4 & $2 \cdot 8$ & $1 \cdot 0$ & 0.005 \\
\hline Total SFA & $46 \cdot 0$ & $7 \cdot 3$ & $45 \cdot 7$ & $5 \cdot 7$ & NS \\
\hline Total MUFA & $36 \cdot 4$ & $6 \cdot 2$ & $37 \cdot 6$ & $3 \cdot 4$ & NS \\
\hline \multicolumn{6}{|l|}{ Phosphatidylcholine } \\
\hline Linoleic & $23 \cdot 6$ & 1.9 & $23 \cdot 2$ & $3 \cdot 0$ & NS \\
\hline$\gamma$-Linolenic & 0.3 & 0.1 & 0.3 & 0.1 & NS \\
\hline Dihomo- $\gamma$-linolenic & 3.0 & 0.5 & 3.0 & 0.7 & NS \\
\hline Arachidonic & $9 \cdot 7$ & 1.9 & $8 \cdot 4$ & 1.6 & NS \\
\hline Total $n-6$ & $36 \cdot 7$ & $1 \cdot 7$ & 34.9 & 2.9 & 0.02 \\
\hline$\alpha$-Linolenic & 0.3 & 0.1 & 0.3 & 0.1 & NS \\
\hline EPA & 0.9 & 0.3 & $1 \cdot 1$ & 0.8 & NS \\
\hline Docosapentaenoic $n-3$ & 1.0 & 0.1 & 0.8 & 0.2 & 0.001 \\
\hline DHA & 2.9 & 0.7 & $3 \cdot 8$ & 1.4 & 0.019 \\
\hline Total $n-3$ & $5 \cdot 2$ & 0.9 & $6 \cdot 0$ & 1.9 & NS \\
\hline Total SFA & $44 \cdot 7$ & 0.8 & 44.5 & 1.4 & NS \\
\hline Total MUFA & $14 \cdot 0$ & $1 \cdot 2$ & $15 \cdot 3$ & $2 \cdot 8$ & NS \\
\hline \multicolumn{6}{|l|}{ Cholesteryl ester } \\
\hline Linoleic & $52 \cdot 8$ & $3 \cdot 2$ & $49 \cdot 3$ & $9 \cdot 9$ & NS \\
\hline$\gamma$-Linolenic & 0.8 & 0.4 & $1 \cdot 1$ & 1.4 & NS \\
\hline Dihomo- $\gamma$-linolenic & $1 \cdot 1$ & 0.4 & 0.9 & 0.5 & NS \\
\hline Arachidonic & $6 \cdot 4$ & 1.4 & $9 \cdot 2$ & $6 \cdot 2$ & NS \\
\hline Total $n-6$ & $61 \cdot 1$ & 3.0 & $60 \cdot 6$ & $8 \cdot 0$ & NS \\
\hline$\alpha$-Linolenic & 0.3 & 0.3 & 0.5 & 0.4 & NS \\
\hline EPA & 0.6 & 0.3 & 0.9 & 0.5 & NS \\
\hline Docosapentaenoic & ND & & ND & ND & NS \\
\hline DHA & 0.4 & 0.2 & 0.6 & 0.3 & NS \\
\hline Total $n-3$ & 1.4 & 0.7 & $2 \cdot 0$ & 0.9 & 0.03 \\
\hline Total SFA & 14.5 & $1 \cdot 7$ & $12 \cdot 2$ & $4 \cdot 2$ & NS \\
\hline Total MUFA & 23.7 & $2 \cdot 0$ & $23 \cdot 6$ & $6 \cdot 4$ & NS \\
\hline \multicolumn{6}{|l|}{ Total plasma lipids } \\
\hline Linoleic & $27 \cdot 1$ & 1.9 & $25 \cdot 6$ & $4 \cdot 1$ & NS \\
\hline$\gamma$-Linolenic & 0.6 & 0.2 & 0.7 & 0.5 & NS \\
\hline Dihomo- $\gamma$-linolenic & 1.5 & 0.5 & $1 \cdot 2$ & 0.3 & NS \\
\hline Arachidonic & 4.8 & 0.8 & $5 \cdot 1$ & 0.2 & NS \\
\hline Total $n-6$ & $34 \cdot 1$ & 1.9 & $32 \cdot 7$ & 3.5 & NS \\
\hline$\alpha$-Linolenic & 0.6 & 0.2 & 0.7 & 0.3 & NS \\
\hline EPA & 0.5 & 0.1 & 0.7 & 0.4 & 0.04 \\
\hline Docosapentaenoic $n-3$ & 0.5 & 0.1 & 0.4 & 0.1 & NS \\
\hline DHA & $1 \cdot 2$ & 0.3 & $1 \cdot 7$ & 0.7 & 0.004 \\
\hline Total $n-3$ & $2 \cdot 7$ & 0.4 & 3.5 & $1 \cdot 1$ & 0.006 \\
\hline Total SFA & $34 \cdot 0$ & 2.5 & $33 \cdot 6$ & 1.9 & NS \\
\hline Total MUFA & 29.5 & 2.5 & $30 \cdot 6$ & $2 \cdot 3$ & NS \\
\hline
\end{tabular}




\begin{tabular}{|c|c|c|c|c|c|}
\hline & \multicolumn{5}{|c|}{ Concentration (\% total fatty acids) } \\
\hline & \multicolumn{2}{|c|}{ Men (n 13) } & \multicolumn{2}{|c|}{ Women (n 23) } & \multirow{2}{*}{$\frac{\text { Student's unpaired } t \text { test }}{P}$} \\
\hline & Mean & SD & Mean & SD & \\
\hline \multicolumn{6}{|c|}{ Total lipid concentration $(\mu \mathrm{g} / \mathrm{ml})$} \\
\hline Total triacylglycerol & 362 & 217 & 416 & 250 & NS \\
\hline Total NEFA & 75 & 48 & 209 & 92 & $<0.0001$ \\
\hline Total phosphatidylcholine & 629 & 177 & 821 & 243 & 0.01 \\
\hline Total cholesteryl esters & 850 & 301 & 1139 & 579 & NS \\
\hline
\end{tabular}

ND, not detected; SFA, saturated fatty acids

lipids. The proportion of DPA $n-3$ was $20 \%$ lower in the PC fraction in women than men, but did not differ between genders in plasma TAG, NEFA or CE (Table 4). There was a greater fractional concentration of total $n$-3 PUFA in women compared with men in plasma NEFA (33\%) and CE (43\%), but not in TAG and PC. Overall, the proportion of total $n-3$ PUFA was $30 \%$ greater in women than men (Table 4). The proportion of total $n-6$ PUFA was $5 \%$ lower in women than men in plasma PC, but did not differ in the other lipid fractions that were measured (Table 4). There was, however, no significant difference in the fractional concentration of total $n$-6 PUFA in total plasma lipids (Table 4). There were no significant differences between men and women in any of the other PUFA that were measured, or in total saturated fatty acids and MUFA (Table 4). There were no significant differences in fatty acid content or total lipid concentration between women who used an OCP and those who did not (data not shown).

\section{Discussion}

The results of this study show that the concentration of DHA, but not other $n-3$ PUFA, was significantly greater in women than men, and that the magnitude of this difference was specific to individual lipid classes.

Comparison between the groups of men and women showed similar intakes of macronutrients, micronutrients and individual fatty acids. There is good agreement of these dietary intakes with those previously reported for men and women of a similar age range (Henderson et al. $2003 a, b)$. Although the assessment of nutrient intakes by food-frequency questionnaire may be more susceptible to errors than other methods (Bingham et al. 1994; Welch et al. 2005), for example weighed food intakes, the similarity between the present data and those previously reported (Henderson et al. 2003a,b) indicates that the food-frequency questionnaire used in this study had a comparable level of precision. The present findings also suggest that the individuals who took part in this study are likely to be representative of the general population, at least in terms of dietary habits. Furthermore, any differences in plasma fatty acid composition between men and women would be more likely to reflect differences in metabolism rather than fatty acid intake.

The present findings show that DHA concentration was specifically increased in women compared with men. Giltay et al. (2004b) also showed that DHA concentration was greater in young women than men, although they also reported a lower level of dihomo- $\gamma$-linolenic acid. The present study differs from that of Giltay et al. (2004b) in two key respects: the extent to which the background diet was controlled and the plasma lipid classes studied. In the study reported by Giltay et al. (2004b), the subjects' diet was controlled for $\alpha \mathrm{LNA}$, EPA and DHA intakes, whereas the subjects in the present study consumed their habitual diet. Because both study designs showed a specifically higher DHA concentration in women than men irrespective of the extent to which the subject's diet was controlled, this suggests that the effect of the background diet on differences between genders in plasma DHA concentration is limited.

Giltay et al. (2004b) reported only the fatty acid composition of plasma CE. CE plays an important role in the transport of cholesterol between the tissues, in particular by LDL and HDL. However, plasma TAG, PC and NEFA also represent important transport pools for PUFA in the body. In the fasting state, plasma TAG represents primarily fatty acids secreted by the liver as VLDL, PC is found as a monolayer on all lipoproteins, and NEFA reflects fatty acids released from adipose tissue by hormone-sensitive lipase activity. The findings of the present study suggest, therefore, an increased incorporation of DHA into TAG and PC derived from the liver. Total NEFA concentration was almost 2-fold greater in women than men, possibly reflecting the greater amount of body fat. When combined with the higher proportion of DHA in plasma NEFA, the absolute DHA concentration in plasma NEFA was 4-fold greater in women than men. Because adipose tissue is an important source of fatty acids for assimilation by the liver (Bulow et al. 1999), the greater concentration of DHA in NEFA in women would tend to increase the supply of DHA to the liver during the fasting state for incorporation into other lipid classes such as TAG, PC and CE, which are ultimately secreted in VLDL. We have shown in women that, following an oral dose of $\left[{ }^{13} \mathrm{C}\right] \alpha \mathrm{LNA}$, DHA appears in plasma NEFA from about $72 \mathrm{~h}$ and is detectable for at least 3 weeks (Burdge \& Wootton, 2002).

One possible explanation is that DHA synthesised in the liver was secreted on VLDL and assimilated into adipose tissue following hydrolysis by lipoprotein lipase. Labelled DHA stored in adipose tissue TAG was then released over a prolonged period of time, and possibly taken up by the liver, then re-entering the TAG and VLDL synthesis pathway. If cycling of DHA between adipose tissue and the liver was an important pathway, it would be anticipated that DHA concen- 
tration in the adipose tissue would be greater in women than men. This suggestion is supported by the observation that young women have a higher concentration of DPA $n-3$ and DHA in adipose tissue compared with men (Tavendale et al. 1992; Bolton-Smith et al. 1997). We did not find a difference between men and women in the DHA concentration of the CE fraction. This may reflect the variability of the DHA content of plasma CE and the low concentration of DHA in this lipid class. However, the total $n-3$ PUFA concentration was higher in women than men in plasma CE. When expressed as the absolute fatty acid concentration in the total plasma fatty acids, the concentrations of EPA and DHA were 2-fold greater in women than men, but there was no difference in DPA $n-3$ concentration between groups. Overall, the effect of a greater DHA concentration in these plasma lipid pools in women than men would be to increase the DHA supply to tissues throughout the body.

Since there were no significant differences between groups in the intakes of $\alpha \mathrm{LNA}$, EPA or DHA, one possible explanation for the finding that the concentration of DHA alone was higher in women than men is greater capacity for DHA synthesis in women (Burdge \& Wootton, 2002; Pawlosky et al. 2003) than in men (Emken et al. 1994; Burdge et al. 2003; Hussein et al. 2005). The results of kinetic analysis suggest that conversion from DPA $n-3$ to DHA is specifically upregulated in women compared with men (Pawlosky et al. 2003). This process encompasses the synthesis of 24:5n-3 and $24: 6 n-3$, translocation from the endoplasmic reticulum to peroxisomes and limited $\beta$-oxidation to form DHA (reviewed in Sprecher, 2002). This pathway, in particular the translocation of $24: 6 n-3$ from the endoplasmic reticulum, has been suggested to represent a point of metabolic control distinct from the preceding part of the desaturation and elongation pathway that allows the independent regulation of DHA synthesis (Sprecher, 2002; Burdge, 2004). If so, this may allow increased DHA synthesis and a higher DHA concentration in women, independent of the metabolism of other $n$-3 PUFA. A greater conversion of DPA $n-3$ to DHA may explain the lower concentration of DPA $n-3$ in plasma $\mathrm{PC}$ in women than men.

Previous studies have indicated that oestrogen may modulate the activity of the desaturation and chain-elongation pathway. Oestrogen-replacement therapy in postmenopausal women increased the concentrations of the $n-6$ PUFA dihomo- $\gamma$-linolenic acid and AA in the plasma lipids (Silfverstolpe et al. 1981; Ottosson et al. 1984). The treatment of postmenopausal women with an oestrogen agonist or conjugated equine oestrogens increased the concentration of DHA, but not AA, in plasma CE (Giltay et al. 2004a).

These changes in $n-6$ and $n-3$ PUFA were dependent on the dose of oestrogen, and such dose-dependent effects may explain differences in the specificity of the effects observed in each study. DHA synthesis from $\left[{ }^{13} \mathrm{C}\right] \alpha \mathrm{LNA}$ also appeared to be greater in women using an OCP than those who did not, although the study design did not allow a detailed investigation of this finding (Burdge \& Wootton, 2002). Unfortunately, there was insufficient statistical power in the present study to determine whether use of an oestrogen-based OCP altered the DHA status of women. However, the concentration of total plasma DHA appeared to be about $60 \%$ greater in women who used an oestrogen-based OCP than those who did not, whereas the AA concentration was similar in both groups. Overall, greater oestrogen exposure appears to increase selectively the concentration of DHA in plasma lipids which, in turn, probably reflects a greater capacity for DHA synthesis.

Pregnancy represents a period of increased demand on the mother to supply DHA to the fetus in order to support optimal development, particularly of the central nervous system (Innis, 2000). Pregnancy in women, rats and guinea-pigs is associated with a physiological increase in plasma phospholipid DHA concentration (Burdge et al. 1994, 1994; Postle et al. 1995; Otto et al. 1997; Burdge \& Postle, 1994, 1998; Stark et al. 2005), which is the result of adaptations to hepatic phospholipid metabolism (Burdge et al. 1994; Burdge \& Postle, 1998). It is possible that the higher DHA status in women, reflecting a greater capacity for DHA synthesis, may provide DHA for incorporation into phospholipids and in turn for supply to the fetus during pregnancy. This may occur by the establishment of reserves of DHA in the adipose tissue, which can be mobilised during gestation (Al et al. 1997; Herrera, 2000), and/or by synthesis of DHA from its precursors during pregnancy. Because DHA status and synthesis appear to be upregulated by oestrogen (Burdge \& Wootton, 2002; Giltay et al. 2004a), the increase in plasma oestrogens that occurs during gestation may be an important determinant of maternal DHA status and in turn DHA supply to the fetus.

\section{References}

Al MD, van Houwelingen AC \& Hornstra G (1997) Relation between birth order and the maternal and neonatal docosahexaenoic acid status. Eur J Clin Nutr 51, 548-553.

Bingham SA, Gill C, Welch A, Day K, Cassidy A, Khaw KT, Sneyd MJ, Key TJA, Roe L \& Day NE (1994) Comparison of dietary assessment methods in nutritional epidemiology; weighed records v. $24 \mathrm{~h}$ recalls, food-frequency questionnaires and estimated-diet records. Br J Nutr 72, 619-643.

Bolton-Smith C, Woodward M \& Tavendale R (1997) Evidence for age-related differences in the fatty acid composition of human adipose tissue, independent of diet. Eur J Clin Nutr 51, 619-624.

Bulow J, Simonsen L, Wiggins D, Humphreys SM, Frayn KN, Powell D \& Gibbons GF (1999) Co-ordination of hepatic and adipose tissue lipid metabolism after oral glucose. J Lipid Res 40, 2034-2043.

Burdge G (2004) $\alpha$-Linolenic acid metabolism in men and women: nutritional and biological implications. Curr Opin Clin Nutr Metab Care 7, 137-144.

Burdge GC, Finnegan YE, Minihane AM, Williams CM \& Wootton SA (2003) Effect of altered dietary n-3 fatty acid intake upon plasma lipid fatty acid composition, conversion of $\left[{ }^{13} \mathrm{C}\right]$ alpha-linolenic acid to longer-chain fatty acids and partitioning towards-oxidation in older men. Br J Nutr 90, 311-321.

Burdge GC, Hunt AN \& Postle AD (1994) Mechanisms of hepatic phosphatidylcholine synthesis in adult rat: effects of pregnancy. Biochem J 303, 941-947.

Burdge GC, Jones AE \& Wootton SA (2002) Eicosapentaenoic and docosapentaenoic acids are the principal products of $\alpha$-linolenic acid metabolism in young men. Br J Nutr 88, 355-363.

Burdge GC \& Postle AD (1994) Hepatic phospholipid molecular species in the guinea pig. Adaptations to pregnancy. Lipids 29, $259-264$. 
Burdge GC \& Postle AD (1998) Pregnancy-associated adaptations to hepatic phosphatidylcholine biosynthesis in the guinea-pig. Comp Biochem Physiol 119B, 265-272.

Burdge GC \& Wootton SA (2002) Conversion of $\alpha$-linolenic acid to eicosapentaenoic, docosapentaenoic and docosahexaenoic acids in young women. Br J Nutr 88, 411-420.

Burdge GC, Wright P, Jones AE \& Wootton SA (2000) A method for separation of phosphatidylcholine, triacylglycerol, non-esterified fatty acids and cholesterol esters from plasma by solid-phase extraction. Br J Nutr 84, 781-787.

Calder PC (2003) n-3 polyunsaturated fatty acids and inflammation: from molecular biology to the clinic. Lipids 38, 342-352.

Emken EA, Adlof RO \& Gulley RM (1994) Dietary linoleic acid influences desaturation and acylation of deuterium-labeled linoleic and linolenic acids in young adult males. Biochim Biophys Acta 1213, 277-288.

Folch JL, Lees M \& Sloane-Stanley GH (1957) A simple method for the isolation and purification of total lipids from animal tissues. J Biol Chem 226, 497-509.

Giltay EJ, Duschek EJ, Katan MB, Zock PL, Neele SJ \& Netelenbos JC (2004a) Raloxifene and hormone replacement therapy increase arachidonic acid and docosahexaenoic acid levels in postmenopausal women. J Endocrinol 182, 399-408.

Giltay EJ, Gooren LJ, Toorians AW, Katan MB \& Zock PL (2004b) Docosahexaenoic acid concentrations are higher in women than in men because of estrogenic effects. Am J Clin Nutr 80, 1167-1174.

Henderson L, Gregory J, Irving K \& Swan G (2003a) National Diet and Nutrition Survey: Adults Aged 19 to 64 Years, vol. 2, Energy, Protein, Carbohydrate, Fat and Alcohol Intake. London: The Stationery Office.

Henderson L, Irving K, Gregory J, Bates CJ, Prentice A, Perks J, Swan G \& Farron M (2003b) National Diet and Nutrition Survey: Adults Aged 19 to 64 Years, vol. 3, Vitamin and Mineral Intake and Urinary Analytes. London: The Stationery Office.

Herrera E (2000) Metabolic adaptations in pregnancy and their implications for the availability of substrates to the fetus. Eur J Clin Nutr 54, Suppl 1, S47-S51.

Hussein N, Ah-Sing E, Wilkinson P, Leach C, Griffin BA \& Millward DJ (2005) Relative rates of long chain conversion of ${ }^{13} \mathrm{C}$ linoleic and $\alpha$-linolenic acid in response to marked changes in their dietary intake in male adults. J Lipid Res 46, 269-280.

Innis SM (2000) The role of dietary n-6 and n-3 fatty acids in the developing brain. Dev Neurosci 22, 474-480.

Lewis RA, Austen KF \& Soberman RJ (1990) Leukotrienes and other products of the 5-lipoxygenase pathway. Biochemisty and relation to pathobiology in human diseases. $N$ Engl J Med 323, 645-655.
Mattsson LA, Silfverstolpe G \& Samsioe G (1985) Fatty acid composition of serum lecithin and cholesterol ester in the normal menstrual cycle. Horm Metab Res 17, 414-417.

Ministry of Agriculture, Fisheries and Food (1997) Dietary Intake of Iodine and Fatty Acids. Food Information Surveillance Sheet 127. London: Ministry of Agriculture, Fisheries and Food.

Mitchell DC, Niu SL \& Litman BJ (2003) Enhancement of G proteincoupled signalling by DHA phospholipids. Lipids 38, 437-443.

Otto SJ, Houwelinger AC, Antal M, Manninen A, Godfrey K, LopezVaramillo P \& Hornstra G (1917) Maternal and neonatal essential fatty acid status in phospholipids: an international comparative study. Eur J Clin Nutr 51, 232-242.

Ottosson UB, Lagrelius A, Rosing U \& von Schoultz B (1984) Relative fatty acids composition of lecithin during postmenopausal replacement therapy - a comparison between ethinyl estradiol and estradiol valerate. Gynecol Obstet Invest 18, 296-302.

Pawlosky R, Hibbeln J, Lin Y \& Salem N (2003) n-3 fatty acid metabolism in women. Br J Nutr 90, 993-994.

Postle AD, Al MDM, Burdge GC \& Hornstra G (1995) The composition of individual molecular species of plasma phosphatidylcholine in human pregnancy. Early Hum Dev 43, 47-58.

Silfverstolpe G, Johnson P, Samsice G, Svanborg A \& Gustafson A (1981) Effects induced by two different estrogens on serum individual phospholipids and serum lecithin fatty acid composition. Horm Metab Res 13, 141-145.

Sprecher H (2002) The roles of anabolic and catabolic reactions in the synthesis and recycling of polyunsaturated fatty acids. Prostaglandins Leukot Essent Fatty Acids 67, 79-83.

Stark KD, Beblo S, Murthy M, et al. (2005) Comparison of bloodstream fatty acid composition from African-American women at gestation, delivery, and postpartum. J Lipid Res 46, $516-525$

Tavendale R, Lee AJ, Smith WC \& Tunstall-Pedoe H (1992) Adipose tissue fatty acids in Scottish men and women: results from the Scottish Heart Health Study. Atherosclerosis 94, 161-169.

Tilley SL, Coffman TM \& Koller BH (2001) Mixed messages: modulation of inflammation and immune responses by prostaglandins and thromboxanes. $J$ Clin Invest 108, 15-23.

Welch AA, Luben R, Khaw KT \& Bingham SA (2005) The CAFE computer program for nutritional analysis of the EPIC-Norfolk food frequency questionnaire and identification of extreme nutrient values. J Hum Nutr Diet 18, 99-106.

Welch AA, Lund E, Amiano P, et al. (2002) Variability of fish consumption within the 10 European countries participating in the European Investigation into Cancer and Nutrition (EPIC) study. Public Health Nutr 5, 1273-1285. 